Please do not remove this page

RMIT

UNIVERSITY

\title{
Acoustic measurement of a 3D printed micro-perforated panel combined with a porous material
}

Liu, Zhengqing; Zhan, Jiaxing; Fard, Mohammad; Davy, John

https://researchrepository.rmit.edu.au/esploro/outputs/9921860530201341/filesAndLinks?institution=61RMIT_INST\&index=null

Liu, Z., Zhan, J., Fard, M., \& Davy, J. (2017). Acoustic measurement of a 3D printed micro-perforated panel combined with a porous material. Measurement, 104, 233-236.

https://doi.org/10.1016/j.measurement.2017.03.032

Document Version: Accepted Manuscript

Published Version: https://doi.org/10.1016/j.measurement.2017.03.032

Repository homepage: https://researchrepository.rmit.edu.au

(c) 2017 Elsevier Ltd. All rights reserved.

Downloaded On 2023/04/27 01:26:51 +1000

Please do not remove this page 
Thank you for downloading this document from the RMIT Research Repository.

The RMIT Research Repository is an open access database showcasing the research outputs of RMIT University researchers.

RMIT Research Repository: http://researchbank.rmit.edu.aul

\section{Citation:}

Liu, Z, Zhan, J, Fard, M and Davy, J 2017, 'Acoustic measurement of a 3D printed micro-perforated panel combined with a porous material', Measurement, vol. 104, pp. 233-236.

See this record in the RMIT Research Repository at:

https://researchbank.rmit.edu.au/view/rmit:42474

Version: Accepted Manuscript

\section{Copyright Statement:}

(c) 2017 Elsevier Ltd. All rights reserved.

(c) 2017. This manuscript version is made available under the CC-BY-NC-ND 4.0 license http://creativecommons.org/licenses/by-nc-nd/4.0/

Link to Published Version:

http://dx.doi.org/10.1016/j.measurement.2017.03.032 


\title{
Acoustic measurement of a 3D printed polymer micro-perforated panel combined with a porous material
}

\author{
Zhengqing Liu ${ }^{a, \star}$, Jiaxing Zhan ${ }^{a}$, Mohammad Fard ${ }^{a}$ and John Laurence Davy ${ }^{b}$ \\ ${ }^{a}$ School of Engineering, RMIT University, Bundoora 3083, Australia \\ ${ }^{\mathrm{b}}$ School of Science, RMIT University, Melbourne 3001, Australia \\ * Corresponding author. Tel.: +6143056 6611 \\ E-mail address: liu.zhengqing@rmit.edu.au (Z. Liu).
}

\begin{abstract}
The sound absorption coefficient of a micro-perforated panel (MPP) backed by a porous material is investigated in this paper. The feasibility to fabricate MPP samples using 3D printing technology is presented. The test specimens are made of polymer material, and they are printed with different perforation ratios. A porous material is added behind the MPP samples. Their sound absorption coefficient is measured by using the impedance tube method. The results obtained are theoretically validated by using the transfer matrix method (TMM). The results show that the sound absorption coefficient of a 3D printed MPP backed by a porous material agrees fairly well with the theoretical model. By adjusting the perforation ratio, polymer MPP absorbers with high absorption peaks can be implemented. The results in this paper provide a new approach for fabricating MPP sound absorbers for acoustic applications.
\end{abstract}

Keywords: Micro-perforated panel, Porous material, 3D printing technology, Impedance tube method, Sound absorption coefficient

\section{Introduction}

Micro-perforated panel (MPP) sound absorbers have been widely used in acoustic design to protect the porous material and to tune the sound absorption peak frequency. They are thin panels perforated with submillimeter holes, to increase the viscous and thermal losses inside the perforations. They provide high acoustic resistance and low acoustic mass reactance to tune the sound absorption peak frequency. MPP absorbers were first proposed by Maa [1], who established the approximate theory and general theory to predict the acoustic properties of MPP absorbers [2], [3]]. An equivalent circuit model is usually used for modeling the acoustic mechanism of an MPP absorber, although the impedance of the rigidly backed air cavity or sound absorbing material behind the MPP layer is calculated using the transfer matrix method (TMM). The well-known equivalent fluid model (JohnsonChampoux-Allard theory) can be used to predict the acoustic properties of the porous material [[4]-[6]]. The sound absorption of the multilayered structure can be predicted by using TMM, which can be found in many documents [[7]-[11]]. However, the acoustic properties of an MPP layer backed with a porous material have only occasionally been investigated [[6], [12], [13]]. 
The design of an MPP structure to obtain the desired absorption capabilities is relatively easy, but it is difficultly and costly to fabricate such submillimeter holes by using micro-punch or laser technology. Some literature has presented the infiltration method [[14]], the use of parallel perforated ceramic materials [[15]], and the use of a perforated plate with a micro-filtering mesh [[16]]. There is a lack of reports in the literature on MPP sound absorbers fabricated by using 3D printing technology with polymer material [[17]]. This paper investigates the sound absorption of a 3D printed polymer MPP layer combined with a porous material.

\section{Material and methods}

Four MPP layers were printed using a professional 3D printer (ProJet-7000, 3D-System Inc.) with Stereolithography(SLA) technology. The specimens were printed on a layer by layer approach using the Photopolymerization method. In this study, a fine layer resolution of $0.0254 \mathrm{~mm}$ was used, which has the accuracy of $0.0254-0.05 \mathrm{~mm}$ per $25.4 \mathrm{~mm}$ of part dimension. The polymer material named VisiJet-SL(Clear) supplied by 3D-System Inc. was used. The raw material has the composition of 60$75 \%$ of 4,4 '. Isopropylidenedicyclohexanol(HBPA), $15-25 \%$ of 3-ethyl-3-hydroxymethyl-oxetane, and 1$5 \%$ of a mixture containing triarylsulfonium salts.

The samples' thickness, diameter, and the hole diameter are $1 \mathrm{~mm}, 29 \mathrm{~mm}$, and $0.8 \mathrm{~mm}$, respectively. The test specimens were printed with different hole spacings to create different perforation ratios. Meanwhile, a $4.5 \mathrm{~mm}$ non-woven porous polyfelt material is prepared and punched to the same test diameter of $29 \mathrm{~mm}$. The structural parameters of the MPP specimens and the material properties for the porous material are listed in table 1.

Table 1

Structural parameters of MPP specimens and material properties for porous material.

\begin{tabular}{|c|c|c|c|c|c|c|}
\hline \multicolumn{5}{|l|}{ MPP layers } & \multicolumn{2}{|l|}{ Porous material } \\
\hline & MPP1 & MPP2 & MPP3 & MPP4 & Material properties & \\
\hline Hole Geometry & & & & & Thickness, $h(\mathrm{~m})$ & 0.0045 \\
\hline Hole spacing, $b(\mathrm{~m})$ & 0.005 & 0.004 & 0.003 & 0.002 & Density, $\rho\left(\mathrm{kg} / \mathrm{m}^{3}\right)$ & 96.60 \\
\hline Hole diameter, $d(\mathrm{~m})$ & 0.0008 & 0.0008 & 0.0008 & 0.0008 & Airflow resistivity, $\sigma\left(\mathrm{N} \cdot \mathrm{s} / \mathrm{m}^{4}\right)$ & 214000 \\
\hline Perforation ratio, $p(\%)$ & 3.50 & 4.80 & 7.20 & 14.60 & Porosity, $\phi(\%)$ & 98 \\
\hline MPP Specimen Geometry & & & & & Tortuosity, $\alpha_{\infty}$ & 1.53 \\
\hline Specimen diameter, $\mathrm{D}(\mathrm{m})$ & 0.0288 & 0.0286 & 0.0285 & 0.0287 & Viscous characteristics length, $\Lambda(\mathrm{m})$ & 0.000056 \\
\hline Thickness, $t(\mathrm{~m})$ & 0.00107 & 0.00108 & 0.00108 & 0.00105 & Viscous characteristics length, $\Lambda^{\prime}(\mathrm{m})$ & 0.000112 \\
\hline
\end{tabular}

The two-microphone impedance tube (Brüel \& Kjær 4206) method is used to measure the absorption coefficient of the MPP backed with a porous material, by ASTM E1050-12 standard [[18]]. In this method, the complex sound reflection coefficient $R$ of a test sample is calculated from the corrected acoustic transfer function, $H_{12}$ between the two microphone positions. The normal incidence sound absorption coefficient, $\alpha_{n}$ is then calculated by $\alpha_{n}=1-|R|^{2}$. 


\section{Theory}

Fig. 1 shows an electro-acoustical equivalent circuit model of an MPP layer backed by a porous material before the rigid wall. This system includes two elements: they are the MPP layer and the porous material. The transfer matrices of each element are independently calculated and then connected to obtain the surface impedance $Z_{s}$ and sound absorption coefficient of the system.
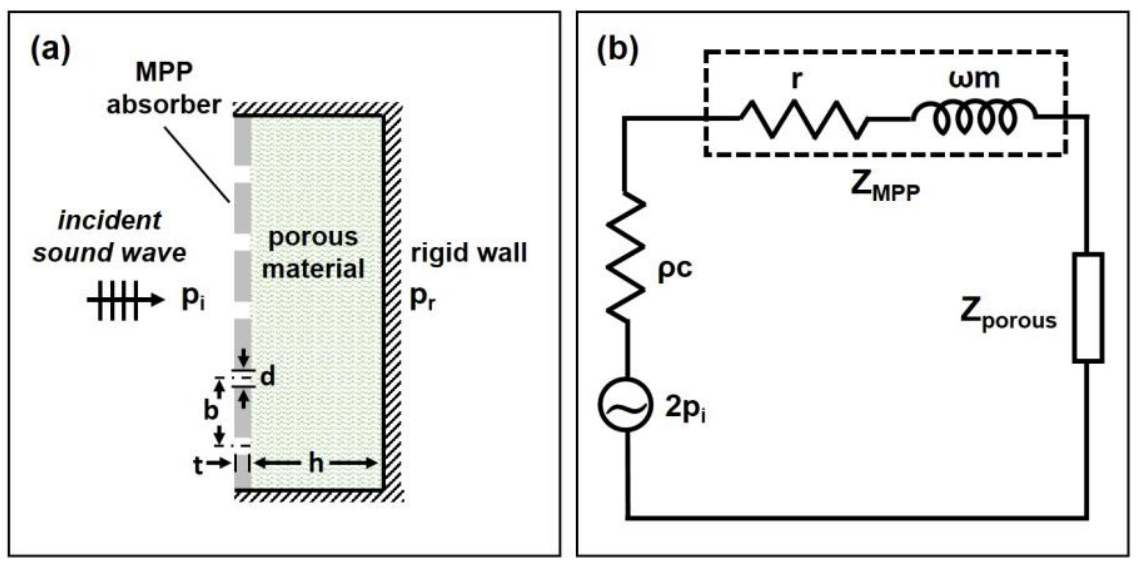

Fig. 1. Schematic diagram of an MPP backed with a porous material (a) and its electro-acoustical equivalent circuit model (b).

The specific acoustic impedance $Z_{M P P}$ of an MPP is derived from the approximate formulas proposed by Maa [1-3]. The specific acoustic impedance $Z_{\text {porous }}$ of the porous material may be obtained from the equivalent fluid model [4-6], and they are given by [11-13]:

$$
\begin{gathered}
Z_{M P P}=\rho c(r+j \omega m) \\
Z_{\text {porous }}=\sqrt{\rho(\omega) K(\omega)}
\end{gathered}
$$

where $\rho c$ is the characteristic impedance of air, $r$ is the relative acoustic resistance; $\omega m$ is relative acoustic mass reactance, $\rho(\omega)$ and $K(\omega)$ are the complex effective density and bulk modulus of a porous material.

Applying the transfer matrix method [10], the total transfer matrix $T_{\text {total }}$ of the system can be obtained by connecting the individual transfer matrices $T_{M P P}$ and $T_{\text {porous }}$ in order [7-11]:

$$
\begin{gathered}
T_{M P P}=\left[\begin{array}{cc}
1 & Z_{M P P} \\
0 & 1
\end{array}\right] \\
T_{\text {porous }}=\left[\begin{array}{cc}
\cos \left(k_{\text {eq }} h\right) & -j Z_{\text {porous }} \sin \left(k_{e q} h\right) \\
\frac{j}{Z_{\text {porous }}} \sin \left(k_{\text {eq }} h\right) & \cos \left(k_{\text {eq }} h\right)
\end{array}\right]
\end{gathered}
$$




$$
T_{\text {total }}=T_{M P P} T_{\text {porous }}=\left[\begin{array}{ll}
T_{11} & T_{12} \\
T_{21} & T_{22}
\end{array}\right]
$$

where $k_{e q}$ is the complex wave number of the porous material, it can be found in the literature [[7]]. The surface impedance and sound absorption coefficient of the system are then calculated by [11]:

$$
\begin{gathered}
Z_{s}=T_{11} / T_{21} \\
\alpha_{n}=\frac{4 \operatorname{Re}\left(Z_{s} / \rho c\right)}{\left[1+\operatorname{Re}\left(Z_{s} / \rho c\right)\right]^{2}+\left[\operatorname{Im}\left(Z_{s} / \rho c\right)\right]^{2}}
\end{gathered}
$$

\section{Results and discussion}

Fig. 2 shows the comparison between the measured and predicted sound absorption coefficients (SAC) of MPP1, MPP2, MPP3, and MPP4 backed with the same porous material sample. The predicted results agree fairly well with the corresponding measurement data for all four MPP specimens. The predicted sound absorption peaks also agree well with the measurement results. This confirms that the polymer MPP layer can be precisely fabricated using 3D printing technology and provide good acoustic sound absorption performance when backed with a porous sound absorbing material.

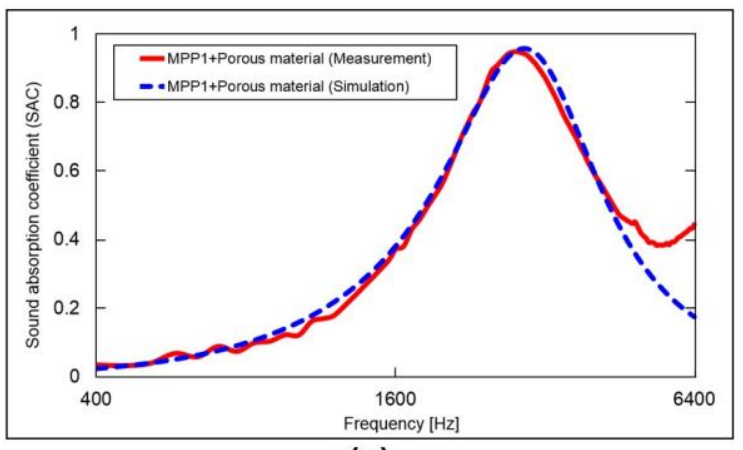

(a)

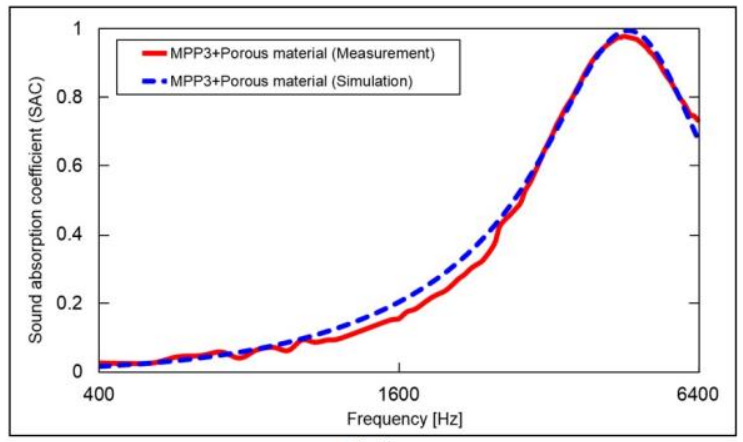

(c)

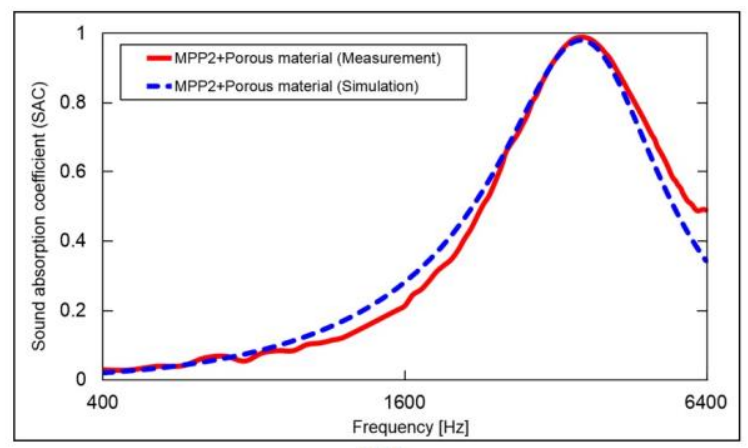

(b)

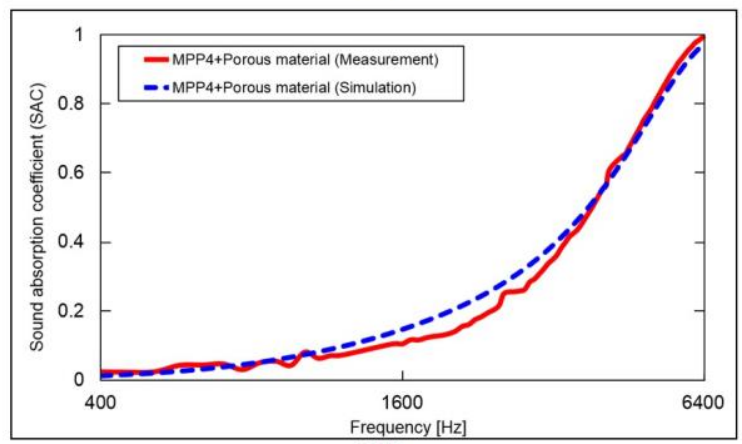

(d)

Fig. 2. Comparison of SAC of the measurement and simulation for an MPP layer backed with a porous material: MPP1 (a), MPP2 (b), MPP3 (c) and MPP4 (d). 

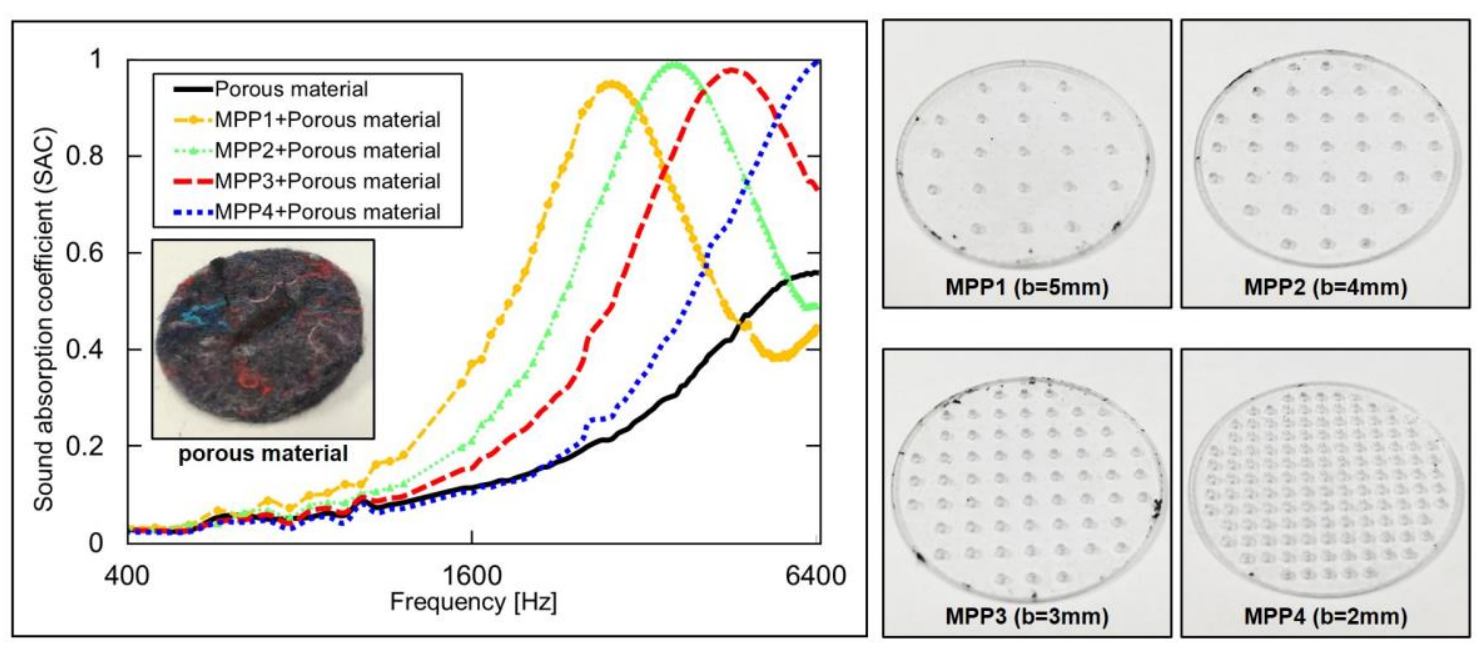

Fig. 3. Effect of perforation ratio of the SAC for an MPP layer backed by a porous material.

The effect of the perforation ratios of the four MPP absorbers on the sound absorption coefficient, when backed by the porous material, is shown in Fig. 3. It can be seen that reducing the hole spacing $b$ of the MPP layer yields a higher acoustic resonance frequency, while the peak sound absorption coefficient is almost constant. Note that the MPP1 with a large hole spacing, $b=5 \mathrm{~mm}$, backed with a porous material has the lowest acoustic resonance at the frequency of $2816 \mathrm{~Hz}$. At lower frequencies, a smaller perforation ratio of MPP layer gives a better sound absorption coefficient whereas a higher perforation ratio can control the absorption at higher frequencies. The MPP layer increases the peak sound absorption coefficient compared to the porous material without the MPP layer. The MPP layer provides the acoustic mass reactance which cancels the acoustic stiffness reactance of the layer of the porous material in front of a rigid backing at the peak sound absorption coefficient frequency. An increase of the perforation ratio results in the decrease of the acoustic mass of all the holes and thus increases the resonant frequency at which maximum the sound absorption coefficient occurs. To obtain the desired peak sound absorption coefficient frequency, it is necessary to adjust the perforation ratio of the MPP layer or the thickness of the porous material.

\section{Conclusions}

This paper investigated the sound absorption of an MPP layer backed by a porous material. It is shown that an MPP layer can be produced using 3D printing technology. The sound absorption coefficient of a 3D printed MPP layer backed with a porous material is measured and theoretically predicted. The effects of perforation ratio are presented. It has been shown that the measurement results agree fairly well with the theoretically model. The peak sound absorption frequency could be altered by adjusting the hole spacing of the MPP layer. This paper presents a new approach for fabrication of MPP layers for specific noise control applications. 


\section{Acknowledgments}

This work is supported by Excellerate Australia Ltd. and Futuris Automotive Group (Australia). The authors are also thankful to Mr. Andre Clemann, Mr. Mark Overend, and Mr. Patrick Wilkins for their technical support. Zhengqing Liu is grateful to Mr. Peter Tkatchyk for preparing a series of experiments.

\section{References}

[1] D.Y. Maa, Theory and design of microperforated panel sound-absorbing construction, Sci. Sin. 18 (1975) 5571.

[2] D.Y. Maa, Microperforated panel wide-band absorber, Noise. Cont. Eng. J. 29 (1987) 77-84.

[3] D.Y. Maa, Potential of microperforated panel absorber, J. Acoust. Soc. Am. 104 (1998) 2861-2866.

[4] D.L. Johnson, J. Koplik., and R. Dashen, Theory of dynamic permeability and tortuosity in fluid-saturated porous media, J. Fluid. Mech. 176 (1987) 379-402.

[5] Y. Champoux., and A.F. Allard, Dynamic tortuosity and bulk modulus in air-saturated porous media, J. Appl. Phys, 70 (1991) 1975-1979.

[6] N. Atalla., and J.F. Sgard, Modeling of perforated plates and screens using rigid frame porous models, J. Sound. Vib. 303 (2007) 195-208.

[7] B.H. Song., and J.S. Bolton, A transfer-matrix approach for estimating the characteristic impedance and wave numbers of limp and rigid porous materials, J. Acoust. Soc. Am. 107 (1999) 1131-1152

[8] N. Atalla., and R. Panneton, Acoustic absorption of macro-perforated porous materials, J. Sound. Vib. 243 (2001) 659-678.

[9] D.H. Lee., and Y.P. Kwon, Estimation of the absorption performance of multiple layer perforated panel system by transfer matrix method, J. Sound. Vib. 278 (2004) 847-860.

[10]K. Verdière, R. Panneton, S. Elkoun, T. Dupont., and P. Leclaire, Transfer matrix method applied to the parallel assembly of sound absorbing materials, J. Acoust. Soc. Am. 134 (2013) 4648-4658.

[11]X. Zhao., and X. Fan, Enhance low frequency sound absorption of micro-perforated panel absorbers by using mechanical impedance plates, Appl. Acoust. 88 (2015) 123-128.

[12] K. Sakagami, S. Kobatake, K. Kano, M. Morimoto., and M. Yairi, Sound absorption characteristics of a single microperforated panel absorber backed by a porous absorbent layer, Acoust. Australia. 39 (2011) 95-100.

[13] C.Q. Wang., and Y.S. Choy, Investigation of a compound perforated panel absorber with backing cavities partially filled with polymer materials, J. Vib. Acoust. 137 (2015) 044501-044501-6

[14]P. Cobo., and F.M. Espinosa, Proposal of cheap microperforated panel absorbers manufactured by infiltration, Appl. Acoust. 74 (2013) 1069-1075.

[15]D. Yang, X. Wang., and M. Zhu, The impact of the neck material on the sound absorption performance of Helmholtz resonators, J. Sound. Vib. 333 (2014) 6843-6857.

[16]H. Ruiz, P. Cobo, T. Dupont, B. Martin., and P. Leclaire, Acoustic properties of plates with unevenly distributed macroperforations backed by woven meshes, J. Acoust. Soc. Am. 132 (2012) 3138-3147.

[17]Z. Liu, J. Zhan, M. Fard., and J.L. Davy, Acoustic properties of a porous polycarbonate material produced by additive manufacturing, Mater. Lett. 181 (2016) 296-299.

[18] ASTM E1050-12, Standard test method for impedance and absorption of acoustical materials using a tube, two microphones and a digital frequency analysis system, American National Standards Institution, New York, 2012. 